\title{
Harmonic versus LigaSure hemostasis technique in thyroid surgery: A meta-analysis
}

\author{
ARUN UPADHYAYA ${ }^{1}$, TIANPENG HU ${ }^{1}$, ZHAOWEI MENG $^{1}, \mathrm{XUE} \mathrm{LI}^{1}$, \\ XIANGHUI HE ${ }^{2}$, WEIJUN TIAN ${ }^{2}$, QIANG JIA ${ }^{1}$ and JIAN TAN ${ }^{1}$ \\ Departments of ${ }^{1}$ Nuclear Medicine and ${ }^{2}$ General Surgery, Tianjin Medical \\ University General Hospital, Heping, Tianjin 300052, P.R. China
}

Received February 29, 2016; Accepted May 18, 2016

DOI: $10.3892 /$ br.2016.691

\begin{abstract}
Harmonic scalpel and LigaSure vessel sealing systems have been suggested as options for saving surgical time and reducing postoperative complications. The aim of the present meta-analysis was to compare surgical time, postoperative complications and other parameters between them in for the open thyroidectomy procedure. Studies were retrieved from MEDLINE, Cochrane Library, EMBASE and ISI Web of Science until December 2015. All the randomized controlled trials (RCTs) comparing Harmonic scalpel and LigaSure during open thyroidectomy were selected. Following data extraction, statistical analyses were performed. Among the 24 studies that were evaluated for eligibility, 7 RCTs with 981 patients were included. The Harmonic scalpel significantly reduced surgical time compared with LigaSure techniques (8.79 min; $95 \%$ confidence interval, -15.91 to $-1.67 ; \mathrm{P}=0.02)$. However, no significant difference was observed for the intraoperative blood loss, postoperative blood loss, duration of hospital stay, thyroid weight and serum calcium level postoperatively in either group. The present meta-analysis indicated superiority of Harmonic Scalpel only in terms of surgical time compared with LigaSure hemostasis techniques in open thyroid surgery.
\end{abstract}

\section{Introduction}

Surgery is one of the standard therapies for numerous thyroid diseases. A total of 80,000 thyroidectomies per year are performed in the United States alone (1). The thyroid is the highly vascularized gland and hemostasis is one of the key limiting factors in morbidity and mortality in thyroid surgery. Similar to bleeding, other possible sources of postoperative

Correspondence to: Dr Zhaowei Meng, Department of Nuclear Medicine, Tianjin Medical University General Hospital, 154 Anshan Road, Heping, Tianjin 300052, P.R. China

E-mail: jamesmencius@163.com

Key words: thyroid surgery, Harmonic scalpel, LigaSure, randomized controlled trials morbidity include dysphonia and dysphagia due to recurrent and/or superior laryngeal nerve injury, hypocalcaemia due to parathyroid ischemia or unintended deprivation, postsurgical hemorrhage, wound infection and postoperative pain. However, the risk of perioperative mortality or major disability is extremely low (2-5).

New vessel-sealing systems, including electrothermal bipolar-activated devices [such as LigaSure ${ }^{\circledR}$ (LS)] or ultrasonic systems [such as UltraCision ${ }^{\circledR}$ or Harmonic Focus ${ }^{\circledR}$ devices (HS)] have been applied to thyroid surgery in recent years. The aim was to reduce blood loss, surgical time and length of skin incision. The LS obliterate the lumen by creating a seal using a combination of pressure and electrothermal energy to change the vessel wall structure (6). The HS simultaneously cut and seal vessels by denaturing and coagulating collagen fibers, using mechanical energy such as ultrasound (7). Numerous randomized controlled trials (RCTs) have been testing these two types of devices since 2000. Several reviews exist that evaluate the possible superiority of each individual device in thyroid surgery (8-14). Each exhibited its own limitations; particularly when regarding comparisons made and completeness of evidence. Furthermore, a meta-analysis comparing these two techniques is limited, which made an updated systematic review of the literature desirable.

The aim of the present meta-analysis was to perform a comparison between HS and LS to assess surgical time, postoperative complications and other parameters in thyroid surgery.

\section{Materials and methods}

Meta-analyses principles. The meta-analysis was conducted by adhering to the principles of 'Preferred Reporting Items for Systematic Reviews and Meta-Analyses’ statement $(15,16)$.

Search strategy. Three individual investigators (AU, TH and ZM) searched the electronic databases according to the standards of the Cochrane collaboration. The following databases were searched: MEDLINE, Cochrane Library, EMBASE and ISI Web of Science. No language or time-period limitations were applied. The search was carried out in March 2015. An update on December 2015 yielded no new studies. All the relevant studies were scanned, and all additional studies of 
potential interest were also retrieved. Experienced thyroid surgeons were consulted to ensure that all relevant studies were included.

Eligibility criteria. RCTs that compared the following two hemostasis techniques in open partial and/or total thyroidectomy were included for analysis: Ultrasonic systems (UltraCision ${ }^{\circledR}$, Harmonic Ace ${ }^{\circledR}$, FOCUSTM; Ehticon Endosurgery Inc., Cincinnati, OH, USA; Harmonic Focus ${ }^{\circledR}$; Ethicon, Somerville, NJ, USA; or related systems; HS) and electrothermal bipolar-activated vessel sealing systems (Ligasure Vessel Sealing System ${ }^{\circledR}$, LigaSure ${ }^{\circledR}$ Precise, LigaSure Atlas LS1020, LigaSure ${ }^{\mathrm{TM}}$ LF1212; Valleylab Inc., Covidien, Boulder, CO, USA; or unspecified LigaSure instruments; LS). RCTs assessing methods for minimally invasive or video-assisted surgery were excluded. Eligibility was assessed for each study by two investigators (AU and TH). Any disagreement was resolved by a third investigator following discussion.

Data extraction. A standardized electronic extraction sheet was used to extract the data. The primary outcome parameter was total surgical time. Secondary outcome parameters were as follows: Surgical bleeding, postoperative bleeding, length of hospital stay, thyroid weight and serum calcium level. In one study the serum calcium level was reported in $\mathrm{mg} / \mathrm{dl}$, which was converted to $\mathrm{mmol} / \mathrm{l}$.

From each eligible RCT, the following baseline characteristics were compiled in the database: Study name, publication year, journal reference, country, study design (randomization, allocation concealment and blinding), sample size, baseline data such as age, gender and interventions (intervention groups and surgical experience).

Quality assessment. The risk of bias and quality in each eligible study was assessed by Cochrane's risk of bias tool, including the following 7 areas: Random sequence generation, allocation concealment, blinding of participants and personnel, blinding of outcome assessment, incomplete outcome data, selective reporting and other biases $(17,18)$. Investigators independently assessed the risk of bias in each eligible trial, and a final consensus was reached. A risk of bias graph was drawn, and risk of bias summary was compiled.

Statistical analysis. Statistical analysis was performed and forest plots were generated using the Review Manager software (version 5.3; The Nordic Cochrane Centre, Copenhagen, Denmark). Total surgical time, amount of intraoperative blood loss, postoperative blood loss, duration of postoperative hospital stay, thyroid weight, serum calcium level and the effective size of each trial were assessed by the mean difference (MD) between treatment groups, and pooled as the weighted mean difference (WMD) with $95 \%$ confidence interval (CI) using the inverse variance method. Statistical heterogeneity was tested by using $\chi^{2}$ and $\mathrm{I}^{2}$ tests. When heterogeneity was high $\left(\mathrm{I}^{2}>50 \%\right)$, the random effect model was used; otherwise, the fixed effect model was applied. $\mathrm{P}<0.05$ was considered to indicate a statistically significant difference. The methods by Hozo et al (19) were used to convert median and range estimates into mean and standard deviation.

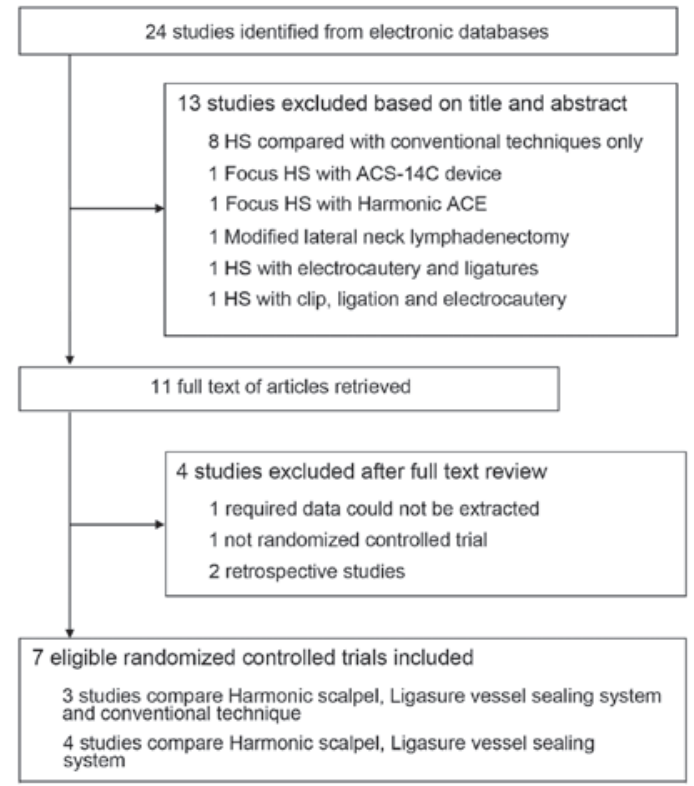

Figure 1. Flowchart diagram of the study selection.

A

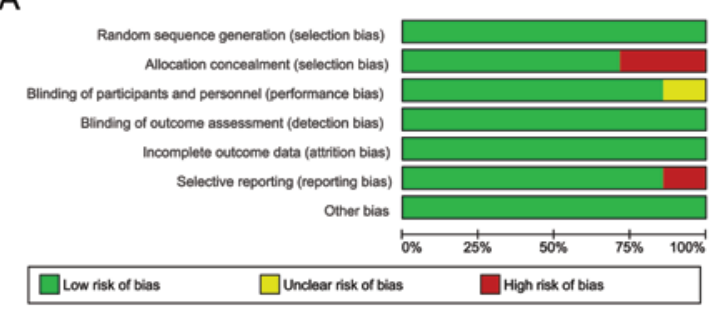

B

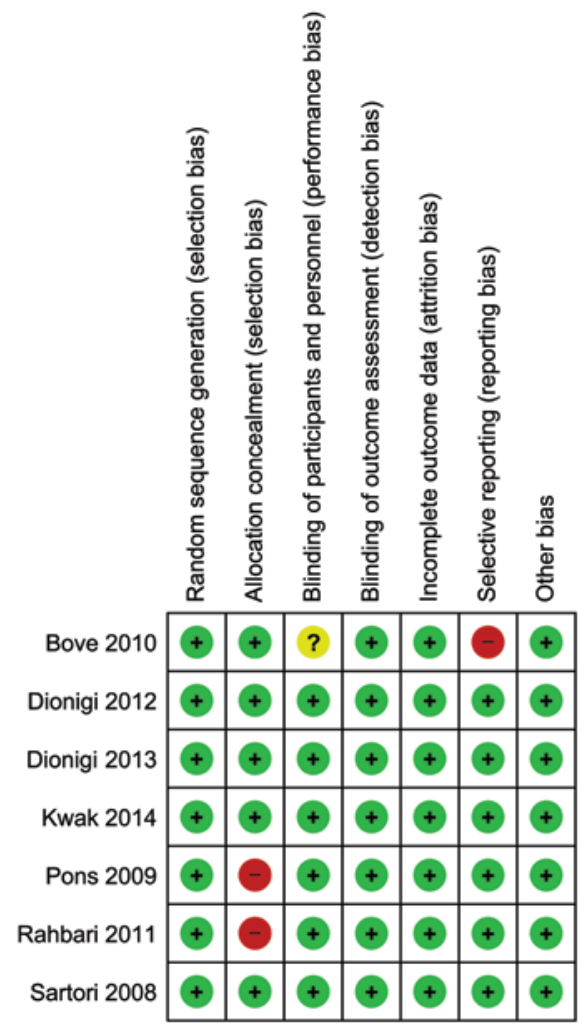

Figure 2. Evaluation of the study quality. Risk of bias (A) graph and (B) summary. The green circle represents the low risk of bias, the yellow circle represents unclear risk of bias, and the red circle represents a high risk of bias. 
Table I. Characteristics of the eligible randomized controlled trials.

\begin{tabular}{lcccccccc}
\hline $\begin{array}{l}\text { First author, } \\
\text { year }\end{array}$ & \multicolumn{3}{c}{$\begin{array}{c}\text { Recruitment } \\
\text { time }\end{array}$} & Interventions & Control & $\begin{array}{c}\text { Surgical } \\
\text { experience }\end{array}$ & $\begin{array}{c}\text { Primary } \\
\text { endpoint }\end{array}$ & $\begin{array}{c}\text { Power analysis } \\
\text { and sample size }\end{array}$ \\
\hline Refs.
\end{tabular}

HF, Harmonic Focus; HAS, Harmonic ACE scalpel; HS, Harmonic scalpel; iPTH, intact parathyroid hormone; LS, LigaSure; LSP, LigaSure Precise; TT, traditional technique; $\mathrm{CH}$, conventional hemostasis; $\mathrm{CT}$, conventional technique.

Table II. Baseline characteristics of the included patients.

First author, year Groups Cases, $n$ Men, $n$ Women, $n$ Mean age \pm SD, years Mean surgical time \pm SD, min Refs.

\begin{tabular}{lcccccc}
\hline Bove, 2010 & HF & 25 & 6 & 19 & $50.5 \pm 12.1$ & $62.7 \pm 14.1$ \\
Dionigi, 2012 & LS & 25 & 7 & 18 & $51.1 \pm 12.1$ & $68.9 \pm 7.4$ \\
& HF & 92 & 17 & 75 & $40.8(20-79)^{\mathrm{a}}$ & $76 \pm 10$ \\
Dionigi, 2013 & LS & 90 & 20 & 70 & $41(20-83)^{\mathrm{a}}$ & $73 \pm 9$ \\
& FS & 96 & 16 & 80 & $43 \pm 11.33$ & $73 \pm 11.33$ \\
Kwak, 2014 & LP & 103 & 24 & 79 & $45 \pm 10.50$ & $85 \pm 13.33$ \\
& HAS & 164 & $20^{\mathrm{b}}$ & $80^{\mathrm{b}}$ & $48.77 \pm 10.74$ & $71.93 \pm 18.26$ \\
Pons, 2009 & LSP & 156 & $15.6^{\mathrm{b}}$ & $84.4^{\mathrm{b}}$ & $49.42 \pm 10.90$ & $75.15 \pm 20.13$ \\
& HS & 20 & NA & NA & NA & $114 \pm 9$ \\
Rahbari, 2011 & LS & 20 & NA & NA & NA & $122 \pm 10$ \\
& HF & 45 & 9 & 36 & $46.1^{\mathrm{c}}$ & $184.2 \pm 66.2$ \\
Sartori, 2008 & LSP & 45 & 9 & 36 & $48.7^{\mathrm{c}}$ & $187.6 \pm 52.6$ \\
& HS & 50 & NA & NA & $56 \pm 14$ & $94 \pm 24$ \\
& LS & 50 & NA & NA & $56 \pm 14$ & $129 \pm 32$
\end{tabular}

${ }^{a}$ Mean value with ranges in parenthesis; ${ }^{b}$ values are $\%$; ${ }^{c}$ values are mean only. HF, Harmonic Focus; HAS, Harmonic ACE scalpel; HS, Harmonic scalpel; FS, Focus Shear; SD, standard deviation; LS, LigaSure; LSP, LigaSure Precise; LP, LigaSure Precise; NA, not available.

\section{Results}

Studies included in the meta-analyses. The electronic literature searches identified 24 potential studies, of which 13 were excluded on the basis of abstract or title. Eleven full-text studies were retrieved. Following further careful scrutiny, 4 were excluded as they did not match the criteria. Seven were considered eligible according to the inclusion criteria (20-26). The detailed search procedure is presented in Fig. 1. Baseline characteristics of the included trials and patients are presented in Tables I and II. There were a total of 981 patients, with 492 in the HS group and 489 in the LS group.
The quality of the included studies was good in terms of sample size, allocation concealment, blinding and other sources of bias (Fig. 2). All the studies applied randomization and provided adequate data for analysis. Surgical experience was described in 5 of the 7 studies. Two studies did not provide any information regarding surgical experience, indicating bias could be possible from this point.

Surgical time. Surgical time was a major outcome of the meta-analysis (Fig. 3). Even though one of the RCTs used surgical time as the time from anesthesia to anesthesia (21), following discussion, the investigators decided that it would not affect the final comparisons. All 7 RCTs (20-26) were 


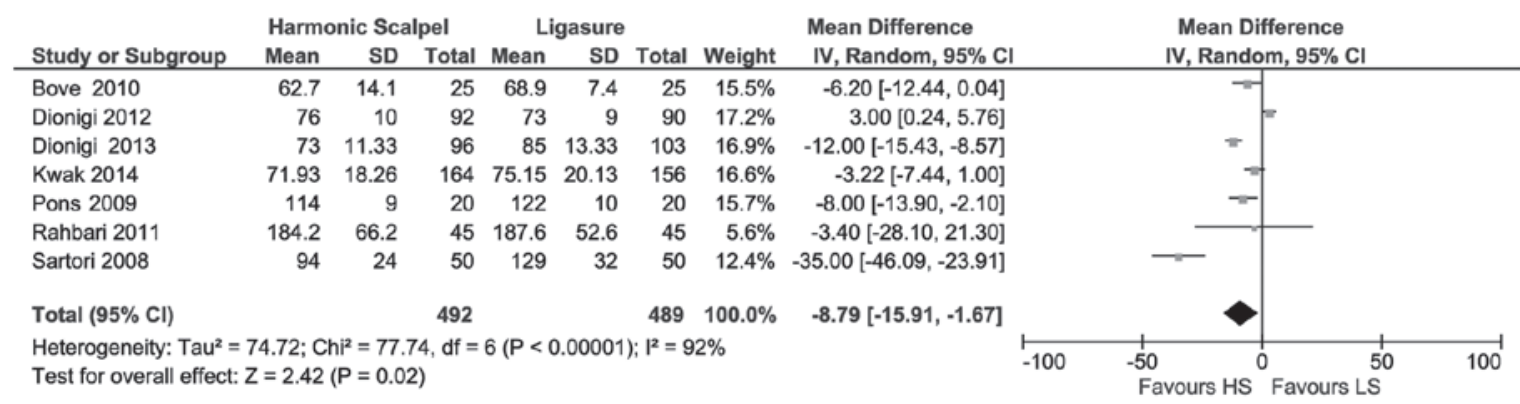

Figure 3. Comparison of surgical time between the Harmonic and LigaSure groups.

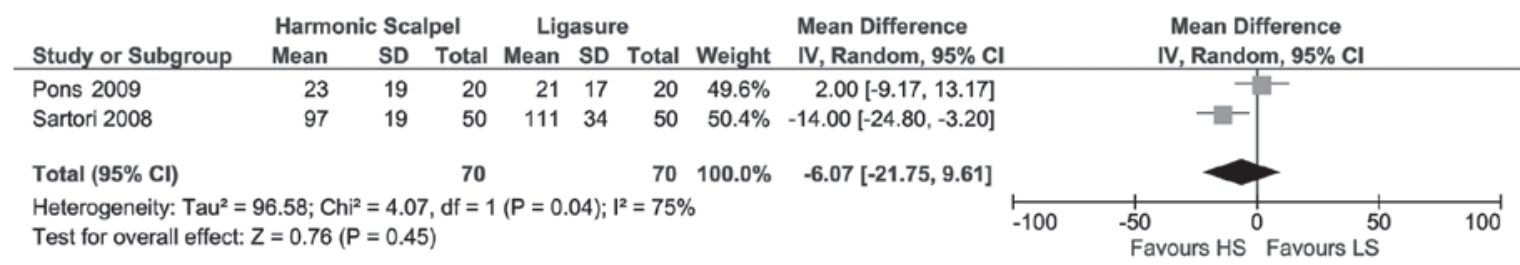

Figure 4. Comparison of intraoperative bleeding the between Harmonic and LigaSure groups.

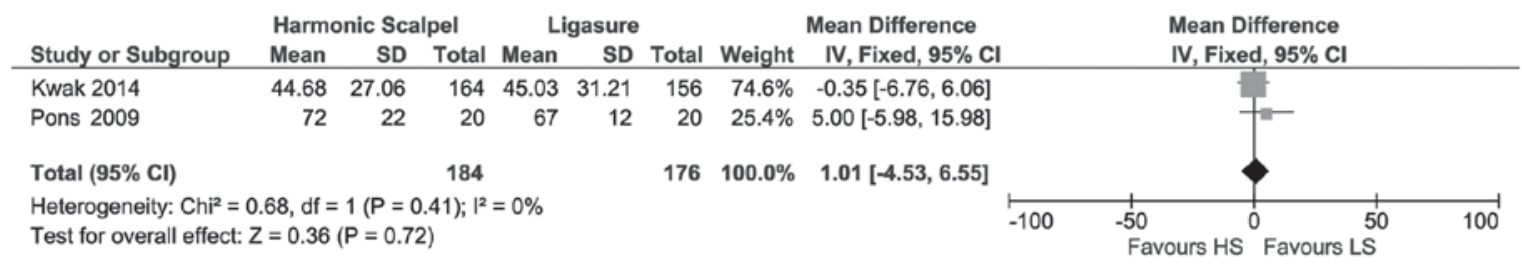

Figure 5. Comparison of postoperative bleeding the between Harmonic and LigaSure groups.

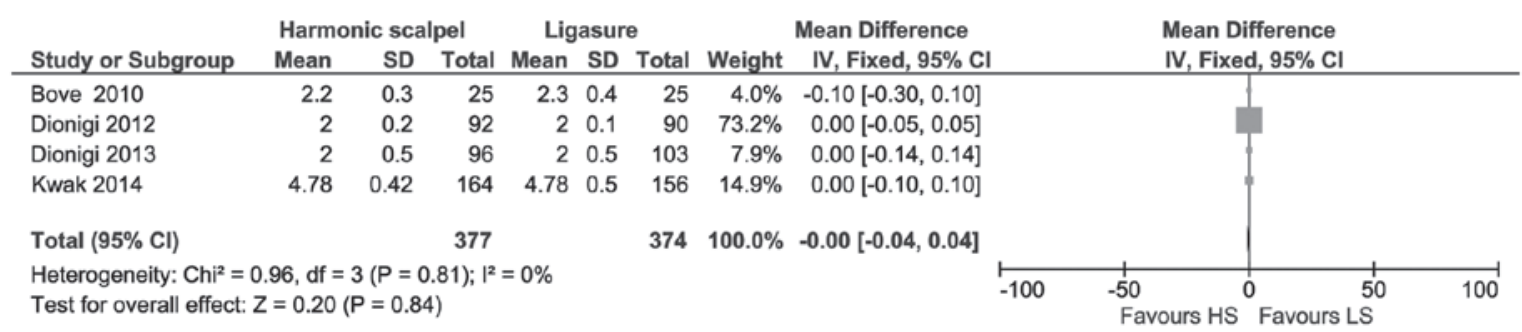

Figure 6. Comparison of hospital stays between the Harmonic and LigaSure groups.

included in the analysis, which demonstrated that surgical time between HS and LS surgery was significantly different (WMD, -8.79 min; $95 \% \mathrm{CI},-15.91$ to $-1.67 ; \mathrm{P}=0.02$ ), as HS was significantly shorter than LS, and the random effect model was used.

Surgical blood loss. No significant differences were observed for intraoperative blood loss between HS and LS. The pooled estimate was $-6.07 \mathrm{ml}$ in intraoperative blood loss $(95 \% \mathrm{CI}$, -21.75 to $9.61 ; \mathrm{P}=0.45$ ) using the random effect model (Fig. 4). In addition, no differences were observed in the postoperative blood loss between HS and LS. The pooled estimate was 1.01 $\mathrm{ml}$ for postoperative blood loss $(95 \% \mathrm{CI},-4.53$ to $6.55 ; \mathrm{P}=0.72)$ using the fixed effect model (Fig. 5).

Hospital stay. No significant differences were observed in the length of hospitalization between HS and LS (WMD,
0.00 days; $95 \% \mathrm{CI},-0.04$ to $0.04 ; \mathrm{P}=0.84)$, and the fixed effect model was applied (Fig. 6).

Thyroid weight. Fig. 7 demonstrated that thyroid weight was not significantly different in the two groups (WMD, $1.78 \mathrm{~g}$; 95\% CI, -0.89 to $4.45 ; \mathrm{P}=0.19)$, and the fixed effect model was applied.

Serum calcium level. As shown in Fig. 8, no significant difference was observed between the serum calcium level in the two groups (WMD, $0.00 \mathrm{mmol} / \mathrm{l} ; 95 \% \mathrm{CI},-0.02$ to $0.02 ; \mathrm{P}=0.80$ ), and the random effect model was applied.

\section{Discussion}

The development of devices, such as HS and LS instruments, has led to shorter surgical time (22). One explanation for the 


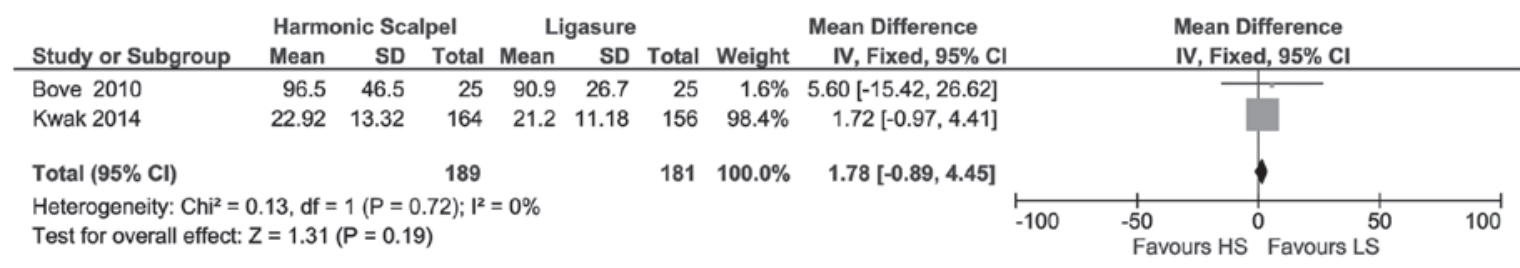

Figure 7. Comparison of thyroid weight between the Harmonic and LigaSure groups.

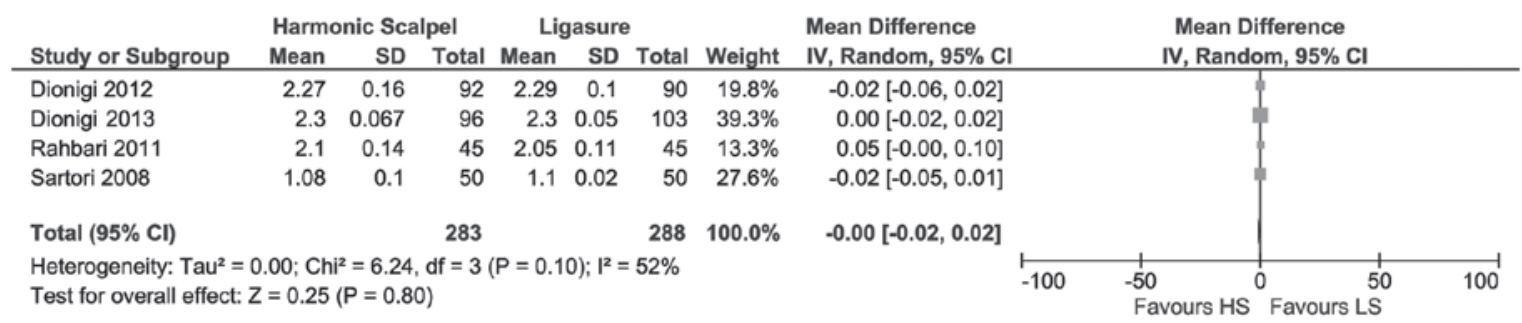

Figure 8. Comparison of serum calcium level between the Harmonic and LigaSure groups.

decrease in the surgical time could be due to reduction in the time required for the hemostasis of the blood vessels of the thyroid gland. Other points such as the experience and expertise of surgeons using these devices could be the reason for the decrease in surgical time. The HS combines hemostasis and cutting in a single instrument, thus avoiding the loss of time when associated with the manipulation of several instruments (22). By contrast, the LS instrument can only be used for hemostasis, and sectioning was performed with other instruments such as scissors (23). McNally et al (27) reported that the surgical time was significantly decreased in the HS group compared with the LS instrument group. This was a retrospective analysis of a prospectively maintained database, so it was excluded in the present analysis. In this study, no significant differences in estimated blood loss, gland weight and hypocalcemia were observed.

HS has been proven to be a safe and useful device in open and video-assisted cervical surgery (28-34). Compared with the standard electric scalpel, HS leads to a shorter surgical time, less lateral thermal spread, and no smoke and no electric energy passage through the body of the patient $(35,36)$. By contrast, the LS system is a method of bipolar hemostasis that denatures the collagen and elastin of the vascular wall and the connecting tissue around the vessels. The tissues are then merged. This technology can coagulate vessels that have a diameter $\leq 7 \mathrm{~mm}(37,38)$. LS is a more time-consuming multiple-sealing approach at the same vessel but HS divides the tissue at the same time of coagulation. HS and LS devices have been developed over the years. In particular, HS has specialized from its previous generations (CS 14) to Focus, while the LS Precise now has a blade, which has led to considerable improvement in surgical time (39). The present study is a meta-analysis comparing the use of the HS and LS technique in thyroid surgery including all available evidences until December 2015. This meta-analysis demonstrated that using the HS systems could significantly reduce surgical time.

Contin et al (39) published a systematic review and meta-analysis comparing HS, LS and a convention technique other in 2013. The study compared HS and LS with the conventional technique, and HS and LS separately. The study concluded that HS and LS were significantly different compared to conventional hemostasis in terms of surgical time. It also concluded that HS was faster in comparison to LS. At present, it is $>2$ years since this meta-analysis was published. The present study identified new evidence from the RCTs by Bove et al (26) in 2013 and Kwak et al (23) in 2014. Therefore, the present study is a more updated meta-analysis comparing HS and LS, including all the currently available RCTs.

It is important to mention the heterogeneity among studies while interpreting the meta-analysis results, as certain differences in methodologies may influence the results. The present meta-analysis included 7 studies, all RCTs. Differences in the experience of surgeons and surgical procedures may have affected the surgical outcomes of the thyroid surgery. Firstly, there were certain differences in the surgical procedures performed in the studies. In the RCT by Bove et al (26), superior thyroid artery was ligated classically when it was $>3 \mathrm{~mm}$. However, in the RCT by Dionigi et al (25), the branches of the superior thyroid vessels were individually divided proximal to the thyroid gland (peripheral ligation) to avoid injuring the external branch of the superior laryngeal nerve and the superior parathyroid gland. The branches of the inferior thyroid artery were divided proximal to the thyroid gland capsule to avoid injuring the recurrent laryngeal nerve and the inferior parathyroid glands. In the cases of the inadvertent removal of a parathyroid gland, the technique of parathyroid auto-transplantation was used. Intraoperative neuro-monitoring of the laryngeal nerves was routinely performed in all the subjects. Secondly, the experience of the surgeon was also an important element affecting the outcome. In the RCT by Bove et al (26), it was reported that harmonic scissors had numerous advantages as it was easier to handle and dissect well while maintaining the advantages of coagulating while cutting. These characteristics were possibly responsible for the reduction in the duration of surgery observed. HS could significantly reduce the surgical time at institutions that performed numerous procedures routinely. It was suggested 
that HS could demonstrate its superiority much better in the hands of experienced surgeons.

The use of HS leading to shorter surgical time has already been established from previous analyses and numerous RCTs $(20,22,26,27,39)$, and the clinical relevance of surgical time as a primary outcome can be questioned from a patient-centered point of view. As individual patients will not be concerned with whether their surgery finishes 8 min earlier or later, it is suggested that upcoming studies should focus on more patient-oriented outcomes such as patient reported voice quality, nerve and parathyroid vasculature preservations rather than surgical time. Procedures during thyroid surgery such as neuro-monitoring may help in the documentation of nerve preservation, which will reflect the thermal spreading property of devices to the adjacent tissues. Reduction of surgical time is a significant advantage for surgical practice as it results in a smaller hospital stay and hospital-related wound infection rate. However, the saving of surgical time has to be set in association with the convenience to a patient, such as higher costs of the device. Since personnel and material costs differ between countries and institutions, every single institution has to reassess the possible benefit of using these devices.

There were certain other limitations in the present study. First, there was a limited number of studies, as well as sample size, which was also a major restriction of the current research. Second, these studies were performed mainly in a single institution. Third, all the devices in the HS and LS category were compared, however, a number of newer devices in the two groups are more efficient compared to their previous versions. As a wide range of trial participants were included by covering male and female patients with typical age ranges, partial and total thyroidectomies, the external validity of these findings are anticipated to be high.

In conclusion, the present study provided a quantitative comparison of HS with LS in thyroid surgery. The results showed a significant reduction of surgical time of HS compared with LS. The postoperative morbidity was not affected. The results of the present study may be useful for high-volume centers performing numerous thyroidectomies every day.

\section{Acknowledgements}

The present study was supported by the National Key Clinical Specialty Project (awarded to the Department of Nuclear Medicine, Radiology and General Surgery). The study was also supported by the Tianjin Medical University General Hospital New Century Excellent Talent Program; Young and Middle-aged Innovative Talent Training Program from Tianjin Education Committee; and the Talent Fostering Program (the 131 Project) from Tianjin Education Committee, Tianjin Human Resources and Social Security Bureau (awarded to Dr Zhaowei Meng).

\section{References}

1. Bhattacharyya $\mathrm{N}$ and Fried MP: Assessment of the morbidity and complications of total thyroidectomy. Arch Otolaryngol Head Neck Surg 128: 389-392, 2002.

2. Chiang FY, Lee KW, Huang YF, Wang LF and Kuo WR: Risk of vocal palsy after thyroidecitomy with identification of the recurrent laryngeal nerve. Kaohsiung J Med Sci 20: 431-436, 2004
3. Lo CY, Kwok KF and Yuen PW: A prospective evaluation of recurrent laryngeal nerve paralysis during thyroidectomy. Arch Surg 135: 204-207, 2000

4. Dedivitis RA, Pfuetzenreiter EG Jr, Castro MA and Denardin OV: Analysis of safety of short-stay thyroid surgery. Acta Otorhinolaryngol Ital 29: 326-330, 2009.

5. Shindo M and Stern A: Total thyroidectomy with and without selective central compartment dissection: A comparison of complication rates. Arch Otolaryngol Head Neck Surg 136: 584-587, 2010.

6. Slakey DP: Laparoscopic liver resection using a bipolar vessel-sealing device: LigaSure. HPB Oxf 10: 253-255, 2008.

7. Meurisse M, Defechereux T, Maweja S, Degauque C, Vandelaer M and Hamoir E: Evaluation of the Ultracision ultrasonic dissector in thyroid surgery. Prospective randomized study. Ann Chir 125: 468-472, 2000 (In French)

8. Macario A, Dexter F, Sypal J, Cosgriff N and Heniford BT: Operative time and other outcomes of the electrothermal bipolar vessel sealing system (LigaSure) versus other methods for surgical hemostasis: A meta-analysis. Surg Innov 15: 284-291, 2008.

9. Yao HS, Wang Q, Wang WJ and Ruan CP: Prospective clinical trials of thyroidectomy with LigaSure vs conventional vessel ligation: A systematic review and meta-analysis. Arch Surg 144: $1167-1174,2009$

10. Cirocchi R, D'Ajello F, Trastulli S, Santoro A, Di Rocco G, Vendettuoli D, Rondelli F, Giannotti D, Sanguinetti A, Minelli L, et al: Meta-analysis of thyroidectomy with ultrasonic dissector versus conventional clamp and tie. World J Surg Oncol 8: 112, 2010.

11. Ecker T, Carvalho AL, Choe JH, Walosek G and Preuss KJ: Hemostasis in thyroid surgery: Harmonic scalpel versus other techniques - a meta-analysis. Otolaryngol Head Neck Surg 143: $17-25,2010$

12. Melck AL and Wiseman SM: Harmonic scalpel compared to conventional hemostasis in thyroid surgery: A meta-analysis of randomized clinical trials. Int J Surg Oncol 2010: 396079, 2010.

13. Zhang ZJ, Zhang P, Tian JH, Li J, Li L, Tian J and Yang KH: Ultrasonic coagulator for thyroidectomy: A systematic review of randomized controlled trials. Surg Innov 17: 41-47, 2010.

14. Garas G, Okabayashi K, Ashrafian H, Shetty K, Palazzo F, Tolley N, Darzi A, Athanasiou T and Zacharakis E: Which hemostatic device in thyroid surgery? A network meta-analysis of surgical technologies. Thyroid 23: 1138-1150, 2013.

15. Moher D, Shamseer L, Clarke M, Ghersi D, Liberati A, Petticrew M, Shekelle P and Stewart LA; PRISMA-P Group: Preferred reporting items for systematic review and meta-analysis protocols (PRISMA-P) 2015 statement. Syst Rev 4: 1, 2015.

16. Moher D, Liberati A, Tetzlaff J and Altman DG; PRISMA Group: Preferred reporting items for systematic reviews and meta-analyses: The PRISMA statement. Int J Surg 8: 336-341, 2010.

17. Higgins JP, Altman DG, Gøtzsche PC, Jüni P, Moher D, Oxman AD, Savovic J, Schulz KF, Weeks L and Sterne JA; Cochrane Bias Methods Group; Cochrane Statistical Methods Group: The Cochrane Collaboration's tool for assessing risk of bias in randomised trials. BMJ 343: d5928, 2011.

18. Hopp L: Risk of bias reporting in Cochrane systematic reviews. Int J Nurs Pract 21: 683-686, 2015.

19. Hozo SP, Djulbegovic B and Hozo I: Estimating the mean and variance from the median, range, and the size of a sample. BMC Med Res Methodol 5: 13, 2005.

20. Sartori PV, De Fina S, Colombo G, Pugliese F, Romano F, Cesana $G$ and Uggeri F: Ligasure versus Ultracision in thyroid surgery: A prospective randomized study. Langenbecks Arch Surg 393: 655-658, 2008.

21. Rahbari R, Mathur A, Kitano M, Guerrero M, Shen WT, Duh QY, Clark $\mathrm{OH}$ and Kebebew E: Prospective randomized trial of ligasure versus harmonic hemostasis technique in thyroidectomy. Ann Surg Oncol 18: 1023-1027, 2011.

22. Pons Y, Gauthier J, Ukkola-Pons E, Clément P, Roguet E, Poncet JL and Conessa C: Comparison of LigaSure vessel sealing system, harmonic scalpel, and conventional hemostasis in total thyroidectomy. Otolaryngol Head Neck Surg 141: 496-501, 2009.

23. Kwak HY, Chae BJ, Park YG, Kim SH, Chang EY, Kim EJ, Song BJ, Jung SS and Bae JS: Comparison of surgical outcomes between papillary thyroid cancer patients treated with the Harmonic ACE scalpel and LigaSure Precise instrument during conventional thyroidectomy: A single-blind prospective randomized controlled trial. J Surg Res 187: 484-489, 2014. 
24. Dionigi G, Van Slycke S, Rausei S, Boni L and Dionigi R Parathyroid function after open thyroidectomy: A prospective randomized study for ligasure precise versus harmonic FOCUS. Head Neck 35: 562-567, 2013.

25. Dionigi G, Boni L, Rausei S, Frattini F, Ferrari CC, Mangano A Leotta A and Franchin M: The safety of energy-based devices in open thyroidectomy: A prospective, randomised study comparing the LigaSure ${ }^{\mathrm{TM}}$ (LF1212) and the Harmonic ${ }^{\circledR}$ FOCUS Langenbecks Arch Surg 397: 817-823, 2012.

26. Bove A, Bongarzoni G, Palone G, Di Renzo R, Di Nicola M, Corradetti L and Corbellini L: Comparative study of an electrothermal bipolar vessel sealing system $\left(\right.$ LigaSure $^{\circledR}$ ), a harmonic curved shears (Harmonic Focus ${ }^{\mathrm{TM}}$ ), and traditional technique in total thyroidectomy. Am Surg 76: E94-E96, 2010.

27. McNally MM, Agle SC, Williams RF and Pofahl WE: A comparison of two methods of hemostasis in thyroidectomy. Am Surg 75: 1073-1076, 2009.

28. Manouras A, Lagoudianakis EE, Antonakis PT, Filippakis GM, Markogiannakis $\mathrm{H}$ and Kekis PB: Electrothermal bipolar vessel sealing system is a safe and time-saving alternative to classic suture ligation in total thyroidectomy. Head Neck 27: 959-962, 2005.

29. Kiriakopoulos A, Dimitrios T and Dimitrios L: Use of a diathermy system in thyroid surgery. Arch Surg 139: 997-1000, 2004.

30. Miccoli P: Minimally invasive surgery for thyroid and parathyroid diseases. Surg Endosc 16: 3-6, 2002.

31. Miccoli P, Materazzi G, Fregoli L, Panicucci E, Kunz-Martinez W and Berti P: Modified lateral neck lymphadenectomy: Prospective randomized study comparing harmonic scalpel with clamp-and-tie technique. Otolaryngol Head Neck Surg 140: 61-64, 2009.
32. Siperstein AE, Berber E and Morkoyun E: The use of the harmonic scalpel vs conventional knot tying for vessel ligation in thyroid surgery. Arch Surg 137: 137-142, 2002.

33. Voutilainen PE and Haglund $\mathrm{CH}$ : Ultrasonically activated shears in thyroidectomies: A randomized trial. Ann Surg 231: 322-328, 2000.

34. Dralle H, Sekulla C, Haerting J, Timmermann W, Neumann HJ, Kruse E, Grond S, Mühlig HP, Richter C, Voss J, et al: Risk factors of paralysis and functional outcome after recurrent laryngeal nerve monitoring in thyroid surgery. Surgery 136: 1310-1322, 2004

35. Boddy SA, Ramsay JW, Carter SS, Webster PJ, Levison DA and Whitfield HN: Tissue effects of an ultrasonic scalpel for clinical surgical use. Urol Res 15: 49-52, 1987.

36. Gossot D: Ultrasonic dissectors in endoscopic surgery. Ann Chir 52: 635-642, 1998 (In French).

37. Youssef T, Mahdy T, Farid M and Latif AA: Thyroid surgery: Use of the LigaSure Vessel Sealing System versus conventional knot tying. Int J Surg 6: 323-327, 2008.

38. Lachanas VA, Prokopakis EP, Mpenakis AA, Karatzanis AD and Velegrakis GA: The use of Ligasure Vessel Sealing System in thyroid surgery. Otolaryngol Head Neck Surg 132: 487-489, 2005.

39. Contin P, Gooßen K, Grummich K, Jensen K, Schmitz-Winnenthal H, Büchler MW and Diener MK: ENERgized vessel sealing systems versus CONventional hemostasis techniques in thyroid surgery - the ENERCON systematic review and network meta-analysis. Langenbecks Arch Surg 398: 1039-1056, 2013 